\section{Is the "contour specificity" of McCollough effects an example of anomalous transfer? Comments on Sharpe and Tees (1978)}

\section{BORIS CRASSINI}

University of Queensland, St. Lucia, Australia 4067

JACK BROERSE

Mt. Gravatt College of Advanced Education

Messines Ridge Road, Mt. Gravatt, Australia 4122

and

ROBERT P. O'SHEA

University of Queensland, St. Lucia, Australia 4067

In their experiments on orientation-contingent color aftereffects (McCollough effects, after McCollough, 1965), Sharpe and Tees (1978) report data which they claim are inexplicable by all models of McCollough effects, especially those based on neurophysiological evidence of color-spatial analysis in infrahuman visual systems. We wish to make two comments regarding Sharpe and Tees' paper: the first specifically concerns the interpretation of their data, while the second is a more general comment on the rationale of future research into contingent aftereffects advocated by Sharpe and Tees.

Barlow and Hill (1963) proposed an explanation of the motion aftereffect involving postexcitatory suppression in those feature detectors sensitive to direction of motion. Since then, similar physiological explanations have been proposed with some success to account for simple visual aftereffects and illusions (Anstis, 1975; Coltheart, 1971; Over, 1971). Despite this success with simple aftereffects, generalization of neural adaptation models to more complex contingent aftereffects has proved less successful. Certain aspects of contingent aftereffects are consistent with known physiological data (e.g., the similarity between orientation and ocular parameters of McCollough effects, and the orientation and ocular parameters of color-coded edge detectors; see review by Over, 1977). However, the persistence of McCollough effects far exceeds the duration of postexcitatory suppression (Maffei, Fiorentini, \& Bisti, 1973; see also Kandel, 1976, Chapters $11,12,13)$. Such durability implies that some more permanent, perhaps structural, alteration is produced in the feature detectors stimulated during induction of McCollough effects (Creutzfeldt, 1973). This notion of neural plasticity has been applied with success to other areas of

Requests for reprints should be sent to Boris Crassini, Department of Psychology, University of Queensland, St. Lucia, Australia 4067. perceptual processing (see reviews by Barlow, 1975; Grobstein \& Chow, 1975). In view of the applicability within the current Zeitgeist of principles of neural plasticity to explanations of contingent aftereffects, it was disturbing to read Sharpe and Tees' claim that their data could not be explained by any model of McCollough effects, including those involving neural plasticity. We suggest that Sharpe and Tees' dismissal of neurophysiological models in general, and those incorporating neural plasticity in particular, may have been premature.

In their study, Sharpe and Tees generated orientation-specific colored aftereffects using two types of inspection and test pattern. The first consisted of the gratings of black and white bars typically used to produce McCollough effects. The second type of pattern comprised similar gratings, but with black bars incomplete (see Figure 1). They report that irrespective of the type of pattern (complete or incomplete) used during the inspection period, the strongest colored aftereffect always occurred when the test stimulus contained complete contours.

In discussing their findings, Sharpe and Tees (1978) state, "Doubtless, learned color associations with interrupted lines could readily generalize to complete lines. The laws of classical conditioning would, indeed, predict such a phenomenon. But these laws would concomitantly predict that a response decrement and not a response increment in aftereffect strength should occur when the stimuli characteristics of the test pattern deviate (within reasonable limits) from those of the inspection stimuli" (p. 457). While these results may appear to be counter to those expected from the "laws of classical conditioning," they are similar to a phenomenon first reported by Krechevsky (1938) and investigated further by

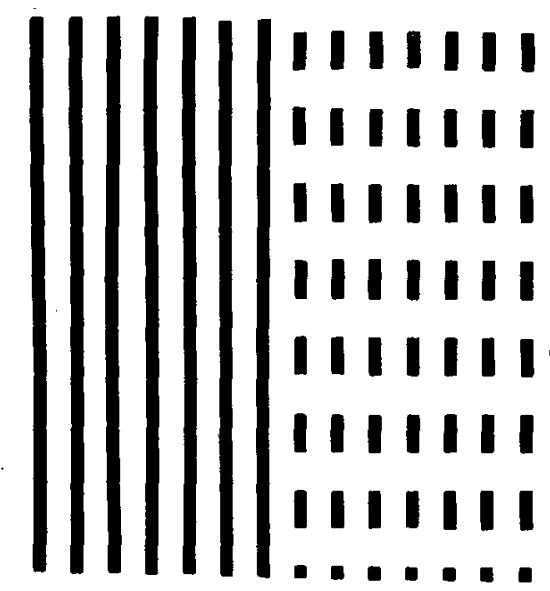

Figure 1. An example of the complete and incomplete stimuli used by Sharpe and Tee (1978). 


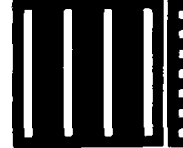

a

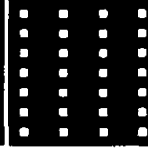

b

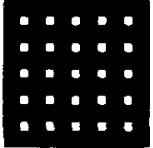

C

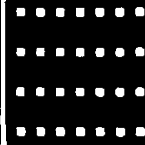

d

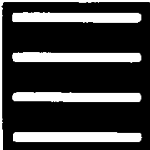

e
Figure 2. Example of stimuli used by Dodwell (1970).

Dodwell (1970, 1977a, 1977b). Using the patterns shown in Figure 2, Dodwell trained rats in a paired discrimination task with, for example, Figure $2 \mathrm{~b}$ (the positive stimulus) and Figure $2 \mathrm{~d}$ as the discrimination pair. When testing for stimulus generalization, Dodwell found that rats responded more frequently to Figure $2 \mathrm{a}$ than to the original positive stimulus (Figure 2b), and termed this "anomalous transfer" as it "violated the expectations that the training positive pattern should be preferred over others" (Dodwell, 1977a, p. 209). It is clear that the behavior of Sharpe and Tees' human observers may also be termed anomalous transfer, in that, like Dodwell's rats, they responded maximally to stimuli different from those used during inspection. Thus, Sharpe and Tees may have adopted too narrow a view of conditioning phenomena in dismissing a learning explanation of their data.

A more profitable strategy may have been to modify some model of McCollough effects to incorporate their data, and then to test the consequence of such a modified model. However, Sharpe and Tees seem loath to adopt this or any similar approach, and instead urge researchers to obtain "more information as to the characteristics of the aftereffects, and not to indulge in weak and speculative neurophysiological model building" (p. 457). It is this advice that forms the basis of our second comment. Taken in its broadest sense, Sharpe and Tees' admonition is reminiscent of Bacon's notion of science, free from, for example, the dogma of ancient wisdom and the authority of the Church (see Robinson, 1976, pp. 196-199). With a mind purged of theories or models, the scientist is able to undertake "theoretically neutral observation of nature for the purpose of learning the physical facts of the real world" (Robinson, 1976, p. 198). This view of science was repudiated by Bacon's contemporaries, and more recently by Popper (1963). Without wishing to become embroiled in the Kuhn-Popper debate as to the true nature of science (e.g., see Robinson, 1976, pp. 20-22), it is clear that there is general agreement that data only become "sensible" when interpreted in some theoretical framework (paradigm). To reiterate Lerner's (1976) paraphrase of von Bertalanffy (1933), "a collection of data no more makes a science than does a heap of bricks make a house" (p. 4).

Of course, these comments are based on the most general interpretation of Sharpe and Tees' advice. If their admonition is confined to "weak and speculative neurophysiological model building," we can only agree with their statement and stipulate a further caveat of our own. A common alternative to neural model building is the recourse to explanation of phenomena such as McCollough effects based on unnecessarily elaborate, higher-order constructs. To borrow Sharpe and Tees' words, weak and speculative cognitive model building should also be avoided. For example, Uhlarik, Pringle, and Brigell (1977) reported that orientation-specific colored aftereffects were dependent on the subjectively perceived organization of their test patterns, and argued "that cognitive factors can influence both the nature and extent that the underlying mechanisms ... are involved in the processing of pattern information" (p. 510). Similarly, it could be argued that the "anomalous transfer" reported by Sharpe and Tees is consistent with this notion; that is, that raw sensory data are reconstructed by "cognitive factors" involving rules of organization and structure. While it may be appropriate to conceptualize the process of perception in human observers in these terms, it is difficult to apply this model to the "humble rat, not noted for its acute vision or intellectual prowess" (Dodwell, 1977b, p. 220).

We are aware of the hazards inherent in attempting to extrapolate from similar behaviors in different species to the notion that common mechanisms underlie these behaviors (Washburn, 1978). However, it is more parsimonious to posit a minimal mechanism common to rats and human observers which may mediate the behavior reported by Dodwell, and Sharpe and Tees, respectively. One such "minimal mechanism" is that proposed by Dodwell to underlie anomalous transfer in rats, namely, orientation detectors of the type discovered by Hubel and Wiesel (1962). As we reported in the opening paragraphs, similar mechanisms have been implicated in explanations of human perceptual effects. In addition to the value of parsimony, this minimal mechanism has the advantage of generating testable hypotheses, the outcomes of which can be used to refute or modify the model.

In conclusion, we feel that Sharpe and Tees have overemphasized the "negative" aspects of their results. The more "positive" aspects become apparent through the recognition of the similarity between their data (gathered in an experimental paradigm concerned with perceptual processing) and those of Dodwell collected within a learning paradigm. On this basis, Sharpe and Tees' results lend support to the notion (see Skowbo, Timney, Gentry, \& Morant, 1975) that McCollough effects may form "missing links" between learning and perception and that 
investigation of these effects may provide insights into the nature of mechanisms common to both phenomena.

\section{REFERENCES}

Anstis, S. M. What does visual perception tell us about visual coding? In M. S. Gazzaniga \& C. Blakemore (Eds.), Handbook of psychobiology. New York: Academic Press, 1975. Pp. 269-323.

Barlow, H. B. Visual experience and cortical development. Nature, 1975, 258, 199-204.

BARLOw, H. B., \& HrL., R. M. Evidence for a physiological explanation of the waterfall phenomenon and figural aftereffects. Nature, 1963, 200, 1434-1435.

Bertalanffy, L. von. Modern theories of development. London: Oxford University Press, 1933.

Coltheart, M. Visual feature-analysers and aftereffects of tilt and curvature. Psychological Review, 1971, 78, 114-121.

Creutzreldt, O. D. Some neurophysiological considerations concerning memory. In H. P. Zippel (Ed.), Memory and transfer of information. New York: Plenum Press, 1973.

DoDwell, P. C. Anomalous transfer after pattern discrimination training in rats and squirrels. Journal of Comparative and Physiological Psychology, 1970, 71, 42-51.

DoDWELL, P. C. Pattern structure and relational discrimination learning. Perception, 1977, 6, 209-212. (a)

DODWELL, P. C. What the rat's eye tells the rat's brain. Perception, 1977, 6, 219-220. (b)

Grobstein, P., \& Chow, K. L. Receptive field development and individual experience. Science, 1975, 190, 352-358.

Hubel, D. H., \& Wiesel, T. N. Receptive fields, binocular interaction and functional architecture in the cat's visual cortex. Joumal of Physiology, 1962, 160, 106-154.

KANDEl, E. R. Cellular basis of behavior. San Francisco: Freeman, 1976.
KRECHEVSKY, I. An experimental investigation of the principle of proximity in the visual perception of the rat. Journal of Experimental Psychology, 1938, 22, 497-523.

LERNER, R. M. Concepts and theories of human development. Reading, Massachusetts: Addison-Wesley, 1976.

MAffei, L., Fiorentini, A., \& Bisti, S. Neural correlate of perceptual adaptation to gratings. Science, 1973, 182, 10361038.

McCollough, C. Color adaptation of edge detectors in the human visual system. Science, 1965, 149, 1115-1116.

OVER, R. Comparison of normalisation theory and neural enhancement explanation of negative aftereffects. Psychological Bulletin, 1971, 75, 225-243.

OVER, R. Contingent aftereffects in the perception of color and contour. In R. H. Day \& G. V. Stanley (Eds.), Studies in perception. Perth: University of Western Australia Press, 1977.

Popper, K. R. Science: Problems, aims, responsibilities. Proceedings of the 47th annual meeting of the Federation of American Societies for Experimental Biology, 1963, 22, 961-972.

RoBinson, D. N. An intellectual history of psychology. New York: Macmillan, 1976.

Sharpe, L. T., \& Tees, R. C. Contour specificity of the McCollough effect. Perception \& Psychophysics, 1978, 23, 451-458.

Skowbo, D., Timney, B. N., Gentry, T. A., \& Morant, R. B. McCollough effects: Experimental findings and theoretical accounts. Psychological Bulletin, 1975, 82, 497-510.

Uhlarik, J., Pringle, R., \& Brigell, M. Color aftereffects contingent on perceptual organization. Perception \& Psychophysics, 1977, 22, 506-510.

WASHBURN, S. L. Human behavior and the behavior of other animals. American Psychologist, 1978, 33, 405-418.

(Received for publication November 1978; accepted December 18, 1978.) 